\title{
Multiaxial Fatigue Life Prediction of GH4169 Alloy Based on the Critical Plane Method
}

\author{
Jianhui Liu ${ }^{1, *}$, Zhen Zhang ${ }^{1},{\text { Bin } \mathrm{Li}^{2} \text { and Shanshan Lang }}^{1}$ \\ 1 School of Mechanical and Electronical Engineering, LanZhou University of Technology, Lanzhou 730050, \\ China; zhangz0618@163.com (Z.Z.); wangmomo21@163.com (S.L.) \\ 2 Gansu construction vocational technical college, Lanzhou 730050, China; binl1976@yeah.net \\ * Correspondence: liujh@lut.edu.cn; Tel.: +86-177-9316-5182
}

Received: 14 January 2019; Accepted: 15 February 2019; Published: 20 February 2019

\begin{abstract}
The multiaxial fatigue life of GH4169 alloy was predicted based on the critical plane method. In this paper, a new critical plane-damage multiaxial fatigue parameter is proposed, in which the maximum shear strain is considered to be the main damage control parameter, and the correction parameter, including the normal stress and strain of the maximum shear strain plane, is defined as the second control parameter. The axis of principle strain rotates under non-proportional loading. Meanwhile, the mechanism of the variation of material microstructure and slip systems leads to an additional hardening phenomenon. The ratio of cyclic yield stress to static yield stress is used to represent cyclic strengthening capacity, and the influence of the phase difference and loading condition on the non-proportional reinforcement effect is considered. It is also proposed that different materials have different influences on the additional hardening phenomenon. Meanwhile, the model revision results in stress under asymmetrical loading. Experimental data of GH4169 alloy show that the proposed model can provide better prediction than the Smith-Watson-Topper (SWT) and Fatemi-Socie (FS) models.
\end{abstract}

Keywords: GH4169 alloy; critical plane method; multiaxial fatigue; additional hardening; mean stress

\section{Introduction}

The high-pressure turbine (HPT) disk is one of the key components of an aero-engine and is important to the structural integrity and reliability of the aero-engine [1-3]. From the viewpoint of design engineering, the safe-life design concept is often introduced and reanalyzed by combining damage tolerance methods with probabilistic approaches [4,5]. Zhu et al. elaborated a new probabilistic fatigue damage accumulation model under random loadings based on a ductility exhaustion model, with probabilistic S-N curves for the high-pressure turbine disc under different flight missions derived based on experimental data of turbine disc alloy GH4169 [6]. Generally, the working environment of the high-pressure turbine blade disc is harsh, and is affected by complex loads such as high rotating speed, high temperature, and abnormal vibration. The damage mechanisms of turbine components often include multiaxial fatigue, creep fracture, high-temperature corrosion, and the interaction of these factors [7]. Considering the multiaxial stress-strain state caused by the irregular surface of the tenon joint structure during engine service, it is particularly important to carry out multiaxial fatigue life predictions of the tenon joint and blade to ensure the structural integrity of the engine turbine. Therefore, it is necessary to establish an accurate prediction model of multiaxial fatigue life. As a common method for predicting multiaxial fatigue life, the critical plane method has proven to be applicable to the prediction and analysis of fatigue life of engineering components under complex stress [8-11]. When fatigue damage accumulates, the component performance decreases gradually, and fatigue failure occurs after long-term operation $[12,13]$. Due to the existence of two independent 
stress-strain components that vary periodically under multiaxial loading, it is difficult to accurately determine the damage caused by loads [14]. Thus, it is of great significance to study the fatigue damage accumulation of components under multiaxial loads. At present, some achievements [15-17] have been made in the study of the cumulative damage rule of multiaxial fatigue, but the geometric structure and loading conditions of actual components are complicated and uncertain [18], and still need further theoretical and experimental studies $[19,20]$.

At present, most multiaxial fatigue life prediction models can accurately predict the fatigue life under proportional loading conditions. However, the principal strain axis rotates continuously under non-proportional loading, and the material microstructure and slip system will change [21], which together lead to additional hardening [22]. This phenomenon has an important influence on the fatigue life of components. At the same time, the additional hardening effects of different materials are different, and are closely related to the layer dislocation energy of materials [23]. On the basis of the different experimental tests, Romanowicz proposed that the phase shift is advantageous or has no effect for brittle or semi-ductile materials, but that it influences the fatigue life for ductile materials [24]. Existing experimental data show that the phase shift shortens the life limit [25]. Therefore, the effect of phase shift must be taken into account when the fatigue life of GH4169 alloy is estimated. The degree of non-proportional additional hardening is not only related to the microstructure and slip of materials, but also the loading history and path. Usually, the additional hardening effect is the most conspicuous when phase difference is $90^{\circ}$. Non-proportional additional hardening complicates the cyclic constitutive relationship of materials and makes it difficult to estimate fatigue life or check strength under multiaxial non-proportional loading. At the same time, actual loads may be asymmetrical to the two axis directions [26-29]. This means that there is an average axial strain and an average shear strain, and they also have significant influence on multiaxial fatigue life, which should be considered in life prediction.

The critical plane method considers the physical significance of crack initiation. Many scholars [22,23,30-32] have proposed a variety of critical plane life prediction models, including the Fatemi-Socie (FS) [33], Wang-Brown (WB) [34], and SWT (Smith-Watson-Topper) models [35]. Initially, Brown et al. [16] proposed a life prediction model with the maximum shear strain plane as the critical plane, which took into account the shear strain and normal strain on the critical plane but did not consider the influence of average stress effect. Based on the above analysis, Wang and Brown modified the mean stress but ignored the impact of the cyclic hardening effect on the service life. In addition, Fatemi and Socie [33] proposed a new model by replacing the normal strain with the normal stress on the critical plane, which more accurately predicted the multiaxial fatigue life of materials with the influence of average stress and cyclic hardening. Smith, Watson, and Topper [35] pointed out that fatigue failure was mainly caused by crack propagation in the plane perpendicular to the maximum principal strain. For tensile cracks, the SWT model has a good life prediction effect, but for pure torsion and multiaxial fatigue, its prediction effect is poor. Wu et al. proposed a new multiaxial fatigue life prediction model by incorporating the concepts of nonlinear continuum damage mechanics and critical plane criteria [36]. Xu et al. asserted the inconvenience of fitting the normal stress sensitivity parameter from additional experimental data and put forward a simple critical plane-based damage parameter with no additional material constants, which attempts to provide a robust method for the multiaxial fatigue analysis of turbine disc alloys [37].

Based on the study of the stress-strain relationship on the critical plane, a new multiaxial fatigue critical plane-damage parameter based on the FS damage parameter is proposed, considering the effect of non-proportional additional hardening and average stress. In the microcosmic aspect, it explains the effects of related parameters on multiaxial fatigue life, rather than being a simple equivalent. In addition, the influence of phase difference and material properties on the additional hardening effect is considered. The enhancement factors related to material constants and phase differences are defined, which can improve the applicability to different loading modes and materials. Meanwhile, the influence of asymmetrical loading on fatigue life is also considered, and it is represented by normal 
mean stress on the critical plane. The results show that the proposed model is feasible for multiaxial fatigue life prediction. With uniaxial fatigue data, the remaining life of components can be estimated, and the costly multiaxial fatigue test can be avoided. Considering the influence of phase difference and material characteristics on the additional hardening phenomenon, the mean stress under asymmetric loading is modified to provide a theoretical basis for practical engineering applications.

\section{The Critical Plane Method}

\subsection{Determination of the Critical Plane of a Smooth Specimen}

Multiaxial smooth fatigue specimens are selected from thin-walled, round tube specimens. The thickness of the sample is smaller than the outer diameter. At this point, the most serious damage plane is always perpendicular to the external plane. The stress-strain state should be indicated by the elastoplastic Poisson ratio $v_{e q}$ when the material is subjected to multiaxial loading and $v_{e q}$ is defined as:

$$
v_{e q}=\frac{v_{e} \varepsilon_{e}+v_{p} \varepsilon_{p}}{\varepsilon_{e}+\varepsilon_{p}}
$$

where $\varepsilon_{e}$ is the elastic phase strain; $\varepsilon_{p}$ is the plastic phase strain; $v_{e}$ is the elastic Poisson ratio; $v_{p}$ is the plastic Poisson ratio.

The strain state under tension-torsion loading can be expressed as follows:

$$
\left(\begin{array}{ccc}
\varepsilon_{x} & \gamma_{x y} / 2 & 0 \\
\gamma_{x y} / 2 & -v_{e q} \varepsilon_{x} & 0 \\
0 & 0 & -v_{e q} \varepsilon_{x}
\end{array}\right)
$$

where $\varepsilon_{x}$ is the positive strain; $\gamma_{x y}$ is the shear strain.

For sine wave loading,

$$
\left\{\begin{array}{l}
\varepsilon_{x}=\varepsilon_{a} \sin \omega t \\
\frac{\gamma_{x y}}{2}=\lambda \frac{\varepsilon_{a}}{2} \sin (\omega t-\varphi)
\end{array}\right.
$$

where $\varepsilon_{a}$ is the axial strain; $\varphi$ is the phase difference; $\lambda$ is the ratio of shear strain to axial strain.

The shear strain and normal strain in any plane, which is determined from the angle $\theta$ between the axis of the specimen and the selected plane, are shown in Equation (4) and Equation (5):

$$
\begin{gathered}
\frac{\gamma_{\max }(\theta)}{2}=\frac{\varepsilon_{a}}{2}\left\{\left[\lambda \cos 2 \theta \cos \varphi-\left(1+v_{e q}\right) \sin 2 \theta\right]^{2}+(\lambda \cos 2 \theta \sin \varphi)^{2}\right\}^{1 / 2} \sin (\omega t+\eta) \\
\varepsilon_{n}(\theta)=\frac{\Delta \varepsilon_{a}}{2}\left\{\left[2\left(1+v_{e q}\right) \lambda \cos ^{2} \theta+\lambda \sin 2 \theta \cos \varphi-2 v_{e q}\right]^{2}+(\lambda \sin 2 \theta \sin \varphi)^{2}\right\}^{1 / 2} \sin (\omega t-\xi)
\end{gathered}
$$

where $\gamma_{\max }(\theta) / 2$ is the shear strain on the arbitrary plane; $\varepsilon_{n}(\theta)$ is the normal strain on the arbitrary plane.

The parameters in Equation (4) and Equation (5) are given as follows:

$$
\xi=\arctan \left\{\frac{\lambda \sin 2 \theta \sin \varphi}{1-v_{e q}+\left(1+v_{e q}\right) \cos 2 \theta+\lambda \sin 2 \theta \cos \varphi}\right\}
$$

and

$$
\eta=\arctan \left\{\frac{\lambda \sin 2 \theta \sin \varphi}{\lambda \cos 2 \theta \cos \varphi-\left(1+v_{e q}\right) \sin 2 \theta}\right\} .
$$

From Equations (4) and (5), we know that phase difference between $\gamma_{\max }(\theta) / 2$ and $\varepsilon_{n}(\theta)$ is $\xi+\eta$. The maximum shear strain $\gamma_{\max }(\theta) / 2$ is derived by taking the derivative of Equation (4), that means: 


$$
\begin{gathered}
\frac{1}{2} \frac{\partial \gamma_{\max }(\theta)}{\partial \theta}=0 \\
\theta=\frac{1}{4} \arctan \frac{2 \lambda\left(1+v_{e q}\right) \cos \varphi}{\left(1+v_{e q}\right)^{2}-\lambda^{2}} .
\end{gathered}
$$

Substituting the known values of $v_{e q}, \varphi$, and $\lambda$ into Equation (9), the value of $\theta$ is obtained. There are four options of $\theta$ that take $\gamma_{\max }(\theta) / 2$ as the extreme value in the range of $(-\pi / 2$ to $\pi / 2)$. Two of the values cause shear strain to reach the maximum. Meanwhile, the plane with a larger normal strain is defined as the critical plane, and means:

$$
\varepsilon_{n}=\max \left(\varepsilon_{n}\left(\theta_{1}\right), \varepsilon_{n}\left(\theta_{2}\right)\right) .
$$

\subsection{Determination of the Critical Plane of a Notched Specimen}

For thin-walled tube specimens loaded with continuous functions, theoretical methods can be used to calculate the position of the critical plane. However, for those components which have stress concentration and discontinuous function loading mode, in order to determine the location of the critical plane, the stress-strain state on the arbitrary plane at the danger point should be identified first [38]. For cases with notched members and triangular wave (discontinuous function) loading mode, the critical plane can be determined by the finite element method. The specific steps are as follows:

(1) Elasto-plastic finite element method is used to analyze the mechanics of components, determine the location of danger points, and obtain the strain components $\varepsilon_{i j}$ at danger points.

(2) The stress and strain components of the arbitrary plane (Figure 1) under different working conditions are obtained through coordinate transformation.

$$
\varepsilon^{\prime}=M \varepsilon M^{T}
$$

where $M$ is coordinate transformation matrix; $M^{T}$ is the transpose matrix of matrix $M$.

$$
\boldsymbol{M}=\left[\begin{array}{ccc}
\cos \theta \cos \phi & -\sin \theta & \cos \theta \sin \phi \\
\sin \theta \cos \phi & \cos \theta & \sin \theta \sin \phi \\
-\sin \phi & 0 & \cos \phi
\end{array}\right]
$$

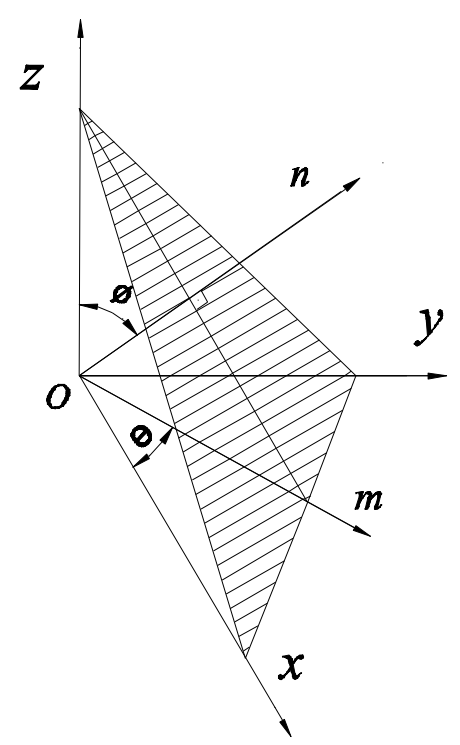

Figure 1. Position of the arbitrary plane. 
(3) The maximum shear strain $\gamma_{i, \max } / 2$ on the $i$-th plane $\left(\theta_{i}, \phi_{i}\right)$ is calculated using the following formula:

$$
\frac{\gamma_{i, \max }}{2}=\frac{1}{2} \max _{\substack{1 \leq j \leq p-1 \\ j+1 \leq m \leq p}}\left\{2 \sqrt{\left[\varepsilon_{x y}(j)-\varepsilon_{x y}(m)\right]^{2}+\left[\varepsilon_{x z}(j)-\varepsilon_{x z}(m)\right]^{2}}\right\}
$$

where $p$ is the load step.

(4) Let $\theta$ change in $(0,-2 \pi), \phi$ in $(0,-\pi)$ according to 1 degree step. Then, the maximum shear strain on the arbitrary plane is calculated and compared. The plane, which has the maximum value of $\gamma_{i, \max } / 2\left(\gamma_{\max } / 2=\max \left(\gamma_{i, \max } / 2\right)\right)$, is defined as the critical plane.

(5) The normal strain/stress on the critical plane is calculated.

This method is not affected by the shape of the structure or the loading mode and can be used to solve the problem of determining the position of the critical plane under various complicated structures and various complicated loading modes. For certain problems that cannot be solved by theoretical methods, this method can achieve good results.

\section{Multiaxial Fatigue Life Prediction Model}

In the multiaxial fatigue life prediction based on the critical plane method, different critical planes are often selected according to different failure modes of fatigue cracks. For the shear failure mode, the maximum shear plane is generally selected as the critical plane, such as the FS model. For the failure mode dominated by tensile cracks, the maximum tensile plane is generally selected as the critical plane, such as the SWT model. Recently, scholars took the maximum damage plane as the critical plane for multiaxial fatigue damage analysis. Since the fatigue crack failure mode of GH4169 alloy in this paper belongs to the shear failure mode [37], the accuracy of multiaxial fatigue life prediction using the SWT model is poor, but the prediction effect using the FS model is conservative.

Fatigue crack initiation is due to the local plastic deformation of the stable slip band. The directions of the slip band and the maximum shear strain are essentially the same. Thus, the maximum shear strain is considered to be a control parameter of the crack initiation. However, the maximum shear strain cannot fully reflect the non-proportional additional hardening effect. Fatemi and Socie considered the maximum normal stress on the maximum shear strain plane to be the second control parameter, and the results are better under proportional and non-proportional loading [33]. For multiaxial fatigue problems of alloy GH4169 under proportional and non-proportional loading, the multiaxial fatigue damage parameter is put forward based on the FS model:

$$
\frac{\gamma_{e q}^{*}}{2}=\frac{\gamma_{\max }}{2}\left(1+\beta \frac{\sqrt{\sigma_{n \cdot \max } E \varepsilon_{n}}}{\sigma_{y}}\right)
$$

where $\gamma_{\max }$ is the maximum shear strain on the critical plane; $\varepsilon_{n}$ is the normal strain on the critical surface; $\sigma_{n \text {.max }}$ is the maximum normal stress on the critical plane; $\sigma_{y}$ is the yield strength; $\beta$ is the parameter related to material which can be fitted using uniaxial fatigue data.

\subsection{Considering Additional Enhanced Multiaxial Damage Parameters}

Under cyclic loading, the material will undergo cyclic strengthening/softening. Its strengthening effect is closely related to loading conditions and material properties. For the static characteristics of materials, the yield stress is usually used to characterize their resistance to deformation. This paper uses the analogy method to introduce the concept of cyclic yield stress $\sigma_{\mathrm{y}}{ }^{\prime}$, in order to compare the response level of materials to cyclic plasticity more directly. The greater the value of the cyclic yield stress $\sigma_{\mathrm{y}}{ }^{\prime}$, the stronger the ability to resist cyclic deformation, and $\sigma_{\mathrm{y}}{ }^{\prime}$ can be expressed as follows:

$$
\sigma_{y}^{\prime}=K^{\prime}\left(\varepsilon_{y}\right)^{\mathrm{n}^{\prime}}
$$


where $K^{\prime}$ is the cyclic strain enhancement factor; $n^{\prime}$ is the cyclic strain enhancement index; $\varepsilon_{y}$ is the strain of the material in yielding.

At the same time, the static and cyclic yield strength will affect the cyclic response level, and then affect the cyclic deformation and strengthening ability. To reflect this, the ratio $\rho$ of the cyclic yield stress to static yield stress is used:

$$
\rho=\sigma_{y}^{\prime} / \sigma_{y} .
$$

The value of $\rho$ indicates the material cycle strengthening ability. Thus, the non-proportional additional hardening effect is influenced by the phase shift and cycle fatigue characteristics. The influence of the two factors should be considered when defining the enhancement factor, and the additional hardening factor is defined as follows:

$$
\mu=1+\rho \cdot \frac{\sigma_{n}}{\sigma_{y}} \cdot \frac{\sin \varphi}{2}=1+\frac{K^{\prime} \sigma_{n} \sin \varphi}{2 \sigma_{y}^{2}}\left(\varepsilon_{y}\right)^{\mathrm{n}^{\prime}}
$$

where $\sigma_{n}$ is the normal stress on the critical plane; $\sigma_{n} / \sigma_{y}$ reflects the effect of loading conditions on the additional hardening effect.

It can be seen from Equation (17) that when under proportional loading, $\mu=1$, there is no additional hardening effect; when phase difference $\varphi=90^{\circ}$, the maximum value of $\mu$ is obtained, and the non-proportional additional hardening effect is the most significant. The effects of $K^{\prime}, n^{\prime}$, and the yield strength of materials on additional hardening are also considered. Combining $\mu$ with Equation (14) is equivalent to a new damage parameter:

$$
\gamma_{e q}^{\prime} / 2=\frac{\gamma_{\max }}{2}\left[1+\frac{K^{\prime} \sigma_{n} \sin \varphi}{2 \sigma_{y}^{2}}\left(\varepsilon_{y}\right)^{\mathrm{n}^{\prime}}\right]\left(1+\beta \frac{\sqrt{\sigma_{n \cdot \max } E \varepsilon_{n}}}{\sigma_{y}}\right)
$$

\subsection{Mean Strain Correction}

From Equations (4) to (7), the normal strain on the critical plane under asymmetric loading conditions can be obtained:

$$
\varepsilon_{n}^{\prime}(\theta)_{\max }=\varepsilon_{n}(\theta)_{\max }+\frac{\varepsilon_{\mathrm{m}} \sin \theta+2 v_{e q} \gamma_{m} \cos \theta}{4}
$$

where $\varepsilon_{\mathrm{m}}$ is the mean normal strain; $\gamma_{m}$ is the mean shear strain.

The normal average strain and stress on the critical plane is obtained by Equation (19):

$$
\begin{gathered}
\varepsilon_{n}^{m}=\frac{\varepsilon_{\mathrm{m}} \sin \theta+2 v_{e q} \gamma_{m} \cos \theta}{2}, \\
\sigma_{n . m}=2 K^{\prime}\left(\varepsilon_{n . m} / 2\right)^{n^{\prime}} .
\end{gathered}
$$

Through the above analysis, the multiaxial fatigue life prediction model can be expressed as follows:

$$
\gamma_{e q}^{\prime} / 2=\frac{\sigma_{f}^{\prime}-\sigma_{n \cdot m}}{E}(2 N)^{b}+\varepsilon_{f}^{\prime}(2 N)^{c} .
$$

\section{Experimental Verification}

In order to verify the accuracy of this multiaxial fatigue life prediction model, experimental results of alloy GH4169 at $650^{\circ}$ in the literature [39] were compared and analyzed. The multiaxial fatigue tests were conducted under proportional and non-proportional loading and the phase differences were $0^{\circ}$, $45^{\circ}$, and $90^{\circ}$. Material performance parameters are shown in Table 1. 
Table 1. Material property parameters [39].

\begin{tabular}{ccccccccc}
\hline Material & $\mathbf{K}^{\prime} / \mathbf{M P a}$ & $\mathbf{n}^{\prime}$ & E/GPa & $\sigma_{y} / \mathbf{M P a}$ & $\sigma_{f}^{\prime} / \mathbf{M P a}$ & $\varepsilon_{f}^{\prime}$ & $\boldsymbol{b}$ & $\boldsymbol{c}$ \\
\hline $\mathrm{GH} 4169$ at $650^{\circ}$ & 1933 & 0.1483 & 182 & 626.4 & 1476 & 0.162 & -0.086 & -0.58 \\
\hline
\end{tabular}

Meanwhile, the FS model and the SWT model are used to predict the fatigue life of alloy GH4169 at $650^{\circ}$. The predicted results of multiaxial fatigue life are compared with experimental values, and the range of 2 times error factor is given. The results are shown in Figure 2:

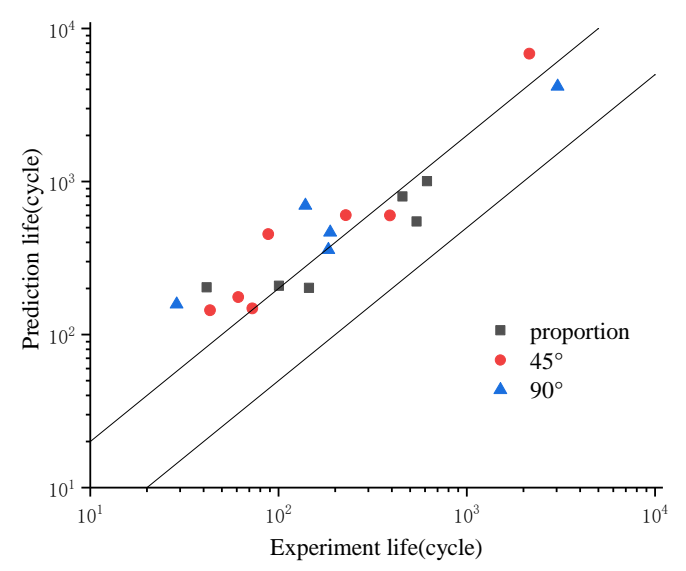

(a) Fatemi-Socie (FS) model.

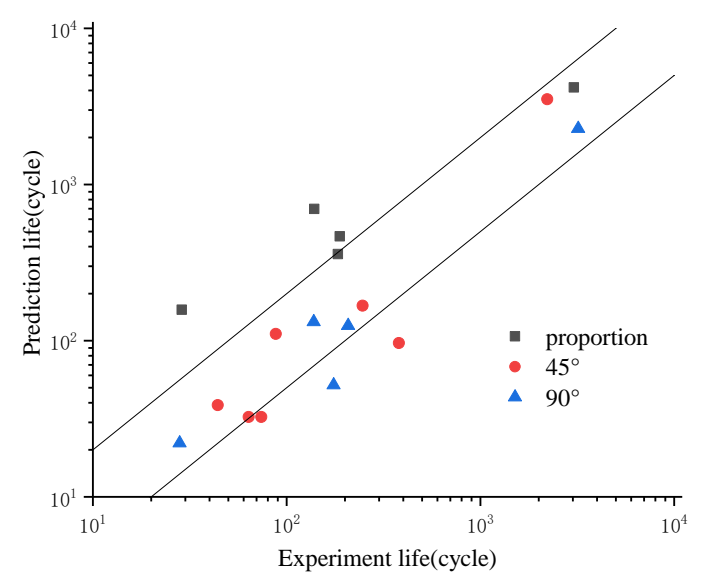

(b) Smith-Watson-Topper (SWT) model.

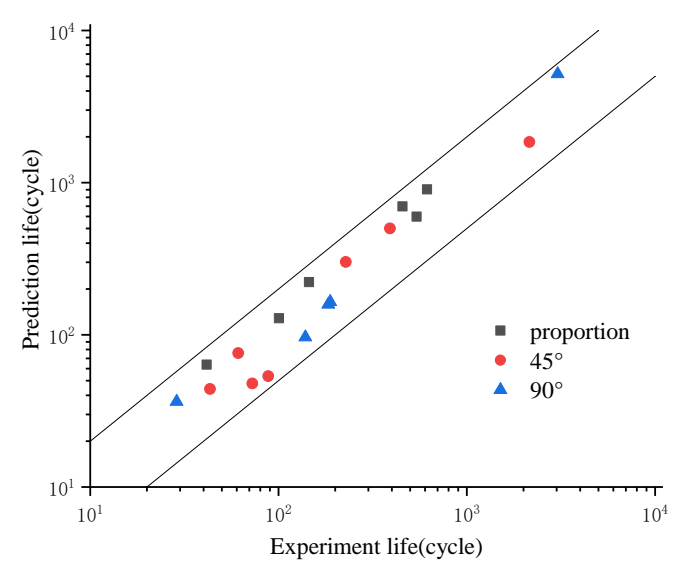

(c) Proposed model.

Figure 2. Comparison of experimental life and model-based predicted life of GH4169 at $650{ }^{\circ} \mathrm{C}$. 
It can be seen from Figure 2 that multiaxial fatigue life predicted by the SWT model is dangerous, while the result predicted by the FS model is conservative. Meanwhile, the proposed model has the best prediction ability for multiaxial fatigue life. In the case of proportional loading, the results predicted by the FS model, most of which are located in the two-factor band, are superior to that of the SWT model. In the case of non-proportional loading, the results from the SWT and FS models are not ideal, outside of the two-factor band (Figure 2a,b). For GH4169 alloy, the agreement between the results of the theoretical predictions and those achieved by experiments is satisfactory (Figure 2c).

\section{Conclusions}

The main conclusions of this research are as follows:

(1) Based on FS damage parameters, a new critical plane multiaxial fatigue damage parameter is proposed by introducing normal stress and normal strain damage parameters on the maximum shear strain plane.

(2) The material cyclic strengthening ability is expressed by the ratio of cyclic yield stress to static yield stress. Meanwhile, the influence of the phase difference and load condition on the non-proportional additional hardening effect is considered. The multiaxial damage parameters, corrected using additional hardening factors, can accurately reflect the influence of additional hardening on the multiaxial fatigue life.

(3) The FS model and the SWT model are not adequate in predicting multiaxial fatigue under non-proportional loading. The experimental results show that the proposed damage parameter method can accurately predict multiaxial fatigue life.

Author Contributions: B.L. put forward the idea of this paper; Z.Z., J.L. and S.L. wrote this paper.

Funding: This research is funded by the Natural Science Foundation of Gansu province, grant number 17JR5RA1220; the National Natural Science Foundation of China, grant number 51605212; and the Project of Hongliu First-Class Disciplines Development Program of Lanzhou University of Technology.

Conflicts of Interest: The authors declare no conflict of interest.

\section{References}

1. Brandão, P.; Infante, V.; Deus, A.M. Thermo-mechanical modeling of a high pressure turbine blade of an airplane gas turbine engine. Procedia Struct. Integrity 2016, 1, 189-196. [CrossRef]

2. Zhu, S.P.; Liu, Q.; Yu, Z.Y.; Liu, Y. Fatigue reliability analysis of a turbine disc under multi-source uncertainties. Procedia Struct. Integrity 2017, 5, 967-972. [CrossRef]

3. Zhu, S.P.; Liu, Q.; Zhou, J.; Yu, Z.Y. Fatigue reliability assessment of turbine discs under multi-source uncertainties. Fatigue Fract. Eng. Mater. Struct. 2018, 41, 1291-1305. [CrossRef]

4. Calvente, M.M.; Blason, S.; Canteli, A.F. A probabilistic approach for multiaxial fatigue criteria. Frattura ed Integrita Strutturale 2017, 11, 160-165. [CrossRef]

5. Correia, J.; Apetre, N.; Arcari, A.; Jesus, A.D.; Muñizcalvente, M.; Rui, C.; Berto, F.; Fernándezcanteli, A. Generalized probabilistic model allowing for various fatigue damage variables. Int. J. Fatigue 2017, 100, 187-194. [CrossRef]

6. Zhu, S.-P.; Liu, Q.; Lei, Q.; Wang, Q. Probabilistic fatigue life prediction and reliability assessment of a high pressure turbine disc considering load variations. Int. J. Damage Mech. 2017, 27, 1569-1588. [CrossRef]

7. Das, J.; Sivakumar, S.M. Multiaxial fatigue life prediction of a high temperature steam turbine rotor using a critical plane approach. Eng. Fail. Anal. 2000, 7, 347-358. [CrossRef]

8. Gates, N.R.; Fatemi, A. On the consideration of normal and shear stress interaction in multiaxial fatigue damage analysis. Int. J. Fatigue 2017, 100, 322-336. [CrossRef]

9. Jiang, C.; Liu, Z.C.; Wang, X.G.; Zhang, Z.; Long, X.Y. A structural stress-based critical plane method for multiaxial fatigue life estimation in welded joints. Fatigue Fract. Eng. Mater. Struct. 2016, 39, 372-383. [CrossRef]

10. Jin, D.; Tian, D.J.; Li, J.H.; Sakane, M. Low-cycle fatigue of 3161 stainless steel under proportional and nonproportional loadings. Fatigue Fract. Eng. Mater. Struct. 2016, 39, 850-858. [CrossRef] 
11. Kamal, M.; Rahman, M.M. Multiaxial fatigue life modelling using hybrid approach of critical plane and genetic algorithm. Fatigue Fract. Eng. Mater. Struct. 2016, 39, 479-490. [CrossRef]

12. Brnić, J.; Turkalj, G.; Čanađija, M.; Lanc, D.; Kršćanski, S.; Brčić, M.; Li, Q.; Niu, J. Mechanical properties, short time creep and fatigue of an austenitic steel. Materials 2016, 9, 298. [CrossRef] [PubMed]

13. Zhang, W.; Liu, H.; Wang, Q.; He, J. A fatigue life prediction method based on strain intensity factor. Materials 2017, 10, 689. [CrossRef] [PubMed]

14. Wei, H.; Liu, Y. A critical plane-energy model for multiaxial fatigue life prediction. Fatigue Fract. Eng. Mater. Struct. 2017, 40, 1973-1983. [CrossRef]

15. Aeran, A.; Siriwardane, S.C.; Mikkelsen, O.; Langen, I. A new nonlinear fatigue damage model based only on s-n curve parameters. Int. J. Fatigue 2017, 103, 327-341. [CrossRef]

16. Brown, M.W.; Miller, K.J. A theory for fatigue failure under multiaxial stress-strain conditions. Proc. Inst. Mech. Eng. 2006, 187, 745-755. [CrossRef]

17. Chu, C.C. Fatigue damage calculation using the critical plane approach. J. Eng. Mater. Technol. 1995, 117, 41-49. [CrossRef]

18. Liao, D.; Zhu, S.-P.; Correia, J.A.F.O.; Jesus, A.M.P.D.; Calçadac, R. Computational framework for multiaxial fatigue life prediction of compressor discs considering notch effects. Eng. Fract. Mech. 2018, 202, 423-435. [CrossRef]

19. Gates, N.; Fatemi, A. Notch deformation and stress gradient effects in multiaxial fatigue. Theor. Appl. Fract. Mech. 2016, 84, 3-25. [CrossRef]

20. Gates, N.R.; Fatemi, A. A simplified cyclic plasticity model for calculating stress-strain response under multiaxial non-proportional loadings. Eur. J. Mech. A/Solid 2016, 59, 344-355. [CrossRef]

21. Lou, Y.; Yoon, J.W.; Huh, H.; Chao, Q.; Song, J.H. Correlation of the maximum shear stress with micro-mechanisms of ductile fracture for metals with high strength-to-weight ratio. Intl. J. Mech. Sci. 2018, 146, 583-601. [CrossRef]

22. Luo, P.; Yao, W.; Susmel, L.; Wang, Y.; Ma, X. A survey on multiaxial fatigue damage parameters under non-proportional loadings. Fatigue Fract. Eng. Mater. Struct. 2017, 40, 1323-1342. [CrossRef]

23. Ma, S.; Markert, B.; Yuan, H. Multiaxial fatigue life assessment of sintered porous iron under proportional and non-proportional loadings. Int. J. Fatigue 2017, 97, 214-226. [CrossRef]

24. Romanowicz, P. Numerical assessment of fatigue load capacity of cylindrical crane wheel using multiaxial high-cycle fatigue criteria. Arch. Appl. Mech. 2017, 87,1-20. [CrossRef]

25. Shang, D.G.; Sun, G.Q.; Chen, J.H.; Cai, N.; Yan, C.L. Multiaxial fatigue behavior of ni-based superalloy gh4169 at 650 c. Mat. Sci. Eng. A Struct. 2006, 432, 231-238. [CrossRef]

26. Pan, J.; Nicholas, T. Effects of mean stresses on multiaxial fatigue life prediction based. Int. J. Fatigue 2001, 23, 87-92. [CrossRef]

27. Brown, M.W.; Surer, D.K.; Wang, C.H. An analysis of mean stress in multiaxial random fatigue. Fatigue Fract. Eng. Mater. Struct. 2010, 19, 323-333. [CrossRef]

28. Ge, J.; Sun, Y.; Zhou, S. Fatigue life estimation under multiaxial random loading by means of the equivalent lemaitre stress and multiaxial s-n curve methods. Int. J. Fatigue 2015, 79, 65-74. [CrossRef]

29. Zhang, J.; Xiao, Q.; Shi, X.; Fei, B. Effect of mean shear stress on torsion fatigue failure behavior of 2a12-t4 aluminum alloy. Int. J. Fatigue 2014, 67, 173-182. [CrossRef]

30. Marciniak, Z.; Rozumek, D.; Macha, E. Verification of fatigue critical plane position according to variance and damage accumulation methods under multiaxial loading. Int. J. Fatigue 2014, 58, 84-93. [CrossRef]

31. Spear, A.D.; Hochhalter, J.D.; Cerrone, A.R.; Li, S.F.; Lind, J.F.; Suter, R.M.; Ingraffea, A.R. A method to generate conformal finite-element meshes from $3 \mathrm{~d}$ measurements of microstructurally small fatigue-crack propagation. Fatigue Fract. Eng. Mater. Struct. 2016, 39, 737-751. [CrossRef]

32. Susmel, L.; Taylor, D. A critical distance/plane method to estimate finite life of notched components under variable amplitude uniaxial/multiaxial fatigue loading. Int. J. Fatigue 2012, 38, 7-24. [CrossRef]

33. Fatemi, A.; Socie, D.F. A critical plane approach to multiaxial fatigue damage including out-of-phase loading. Fatigue Fract. Eng. Mater. Struct. 2010, 11, 149-165. [CrossRef]

34. Wang, C.H.; Brown, M.W. A path-independent parameter for fatigue under proportional and non-proportional loading. Fatigue Fract. Eng. Mater. Struct. 2010, 16, 1285-1297. [CrossRef]

35. Smith, K.N. A stresss train function for the fatigue metals. J. Mater. 1970, 5, 767-778. 
36. Wu, Z.R.; Li, X.; Fang, L.; Song, Y.D. Multiaxial fatigue life prediction based on nonlinear continuum damage mechanics and critical plane method. J. Mater. Eng. Perform. 2018, 1-9. [CrossRef]

37. Xu, S.; Zhu, S.-P.; Hao, Y.-Z.; Liao, D. Critical plane--based multiaxial fatigue life prediction of turbine disk alloys by refining normal stress sensitivity. J. Strain Anal. Eng. 2018, 53, 719-729. [CrossRef]

38. Ranganathan, R.M. An improved, automated finite element analysis for fatigue life predictions of notched components. Int. J. Mater. Prod. Technol. 2004, 21, 539-554. [CrossRef]

39. Xu, S.; Zhu, S.; Hao, Y.; Liao, D. Multiaxial fatigue life prediction of an hpt disk based on critical plane-damage parameters. Acta Aeronautica et Astronautica Sinica 2018, 39, 221930. (In Chinese)

(C) 2019 by the authors. Licensee MDPI, Basel, Switzerland. This article is an open access article distributed under the terms and conditions of the Creative Commons Attribution (CC BY) license (http:/ / creativecommons.org/licenses/by/4.0/). 